University of Nebraska - Lincoln

DigitalCommons@University of Nebraska - Lincoln

June 2006

\title{
Selenium and methionine sulfoxide reduction
}

Hwa-Young Kim

University of Nebraska-Lincoln

Vadim N. Gladyshev

University of Nebraska-Lincoln, vgladyshev@rics.bwh.harvard.edu

Follow this and additional works at: https://digitalcommons.unl.edu/biochemgladyshev

Part of the Biochemistry, Biophysics, and Structural Biology Commons

Kim, Hwa-Young and Gladyshev, Vadim N., "Selenium and methionine sulfoxide reduction" (2006). Vadim Gladyshev Publications. 38.

https://digitalcommons.unl.edu/biochemgladyshev/38

This Article is brought to you for free and open access by the Biochemistry, Department of at DigitalCommons@University of Nebraska - Lincoln. It has been accepted for inclusion in Vadim Gladyshev Publications by an authorized administrator of DigitalCommons@University of Nebraska - Lincoln. 
Published in Selenium: Its molecular biology and role in human health, Second Edition, edited by Dolph L. Hatfield, Marla J. Berry, and Vadim N. Gladyshev. Springer Science+Business Media LLC, 2006. Pages 123-133. Copyright (C) 2006 Springer Science+Business Media LLC. Used by permission.

\title{
Chapter 11
}

\section{Selenium and methionine sulfoxide reduction}

\author{
Hwa-Young Kim \& Vadim N. Gladyshev \\ Department of Biochemistry, University of Nebraska-Lincoln
}

\begin{abstract}
Summary: Methionine residues in proteins can be readily oxidized to a diastereomeric mixture of methionine sulfoxides by reactive oxygen species. In most organisms, methionine sulfoxides are reversibly and stereospecifically reduced back to methionine by two distinct classes of repair enzymes, methionine- $S$-sulfoxide reductase (MsrA) and methionine- $R$-sulfoxide reductase (MsrB). Methionine sulfoxide reduction is thought to be an essential pathway that protects cells from oxidative stress and regulates protein function. This pathway is also implicated in delaying the aging process in organisms from yeast to mammals. The first selenoprotein identified using bioinformatics methods, SelR (also known as SelX or MsrB1), was recently found to be a selenocysteine-containing MsrB. In mammals, selenoprotein MsrB1 is a major MsrB, while MsrB2 and MsrB3 contain cysteine in place of selenocysteine. It has been found that selenocysteine- and cysteine-containing MsrBs employ different catalytic mechanisms. Interestingly, a selenocysteine-containing form of MsrA was also described, but so far was only detected in green algae.
\end{abstract}

\section{Introduction}

Selenium is an essential trace element in humans and other mammals. It is cotranslationally incorporated into proteins in the form of the 21 st amino acid, selenocysteine (Sec) [1-3]. The Sec-containing proteins, selenoproteins, are found in all three kingdoms of life. Twenty five selenoprotein genes have been identified in human and 24 in rodent genomes [4]. A limited number of selenoproteins have been characterized while functions and physiological roles of many other selenoproteins have yet to be determined. Among selenoproteins with known functions the majority are oxidoreductases, for example, glutathione peroxidase [5], thioredoxin reductase [6] and formate dehydrogenase [7]. Selenoproteins typically exhibit 100-1,000 fold higher enzyme activities than their cysteine (Cys) mutants or natural Cys-containing forms. A key reason for the use of Sec in biological systems is explained by this high catalytic activity of Sec-containing enzymes. For incorporation of Sec at in-frame UGA codons, cis- and trans-acting factors are required, including Sec insertion se- 
quence (SECIS) element, SECIS-binding proteins, tRNA ${ }^{[\mathrm{Ser}] \mathrm{Sec}}$, and Sec-specific elongation factor $[3,8]$.

In 1999, initial bioinformatics methods were developed for identification of selenoprotein genes by searching for SECIS elements (see Chapter 9). The first selenoprotein identified using this approach was designated as selenoprotein R (SelR) [9]. Independently, it was described as selenoprotein X (SelX) [10]. Comparative genomic analyses were then used to link the function of SelR to the pathway of methionine sulfoxide reduction, and this prediction was verified experimentally [11].

Proteins can be oxidized by reactive oxygen species (ROS) generated in cells during stress and physiological processes. Methionine residues in proteins are among the most susceptible to oxidation by ROS and are converted by these species to methionine sulfoxide. A diastereomeric mixture of methionine- $S$-sulfoxide and methionine- $R$-sulfoxide is generated by ROS because of the presence of chiral sulfur in methionine sulfoxides [12]. Generation of methionine sulfoxides may manifest significant structural and functional changes in proteins. However, methionine sulfoxide can be reduced back to methionine by repair enzymes, methionine sulfoxide reductases. Therefore, methionine sulfoxide reduction is thought to be an important pathway that protects cells against oxidative stress, regulates protein function, and delays the aging process [13-17].

This chapter will focus on methionine sulfoxide reduction in mammals and the role of selenium in this pathway.

\section{Methionine sulfoxide reductases}

Methionine sulfoxide reductases reduce free and protein-bound methionine sulfoxides back to methionine in the presence of thioredoxin (Trx) or dithiothreitol (DTT) $[18,19]$. To catalyze the repair process, two distinct stereospecific enzymes are evolved. MsrA can only reduce the $S$ epimer of methionine sulfoxide, whereas MsrB is specific for the $R$ form of this amino acid (Figure 1).

Most organisms from bacteria to humans contain MsrA and MsrB genes in their genomes. However, some hyperthermophiles and intracellular parasites do not have MsrA, MsrB, or both proteins [11]. While parasites have access to metabolic pathways of the host, the reason why certain organisms that live at high temperatures lack the methionine sulfoxide reduction system is not understood. MsrA and MsrB genes are clustered in several bacterial genomes and often form an operon. Furthermore, MsrA and MsrB activities are often detected in a single polypeptide formed via direct MsrA/MsrB fusion $[11,20]$. Single MsrA and MsrB genes are present in yeast (e.g., Saccharomyces cerevisiae) and many animals (e.g., Caenorhabditis elegans and Drosophila melanogaster) [11]. On the other hand, multiple MsrA and/or MsrB genes

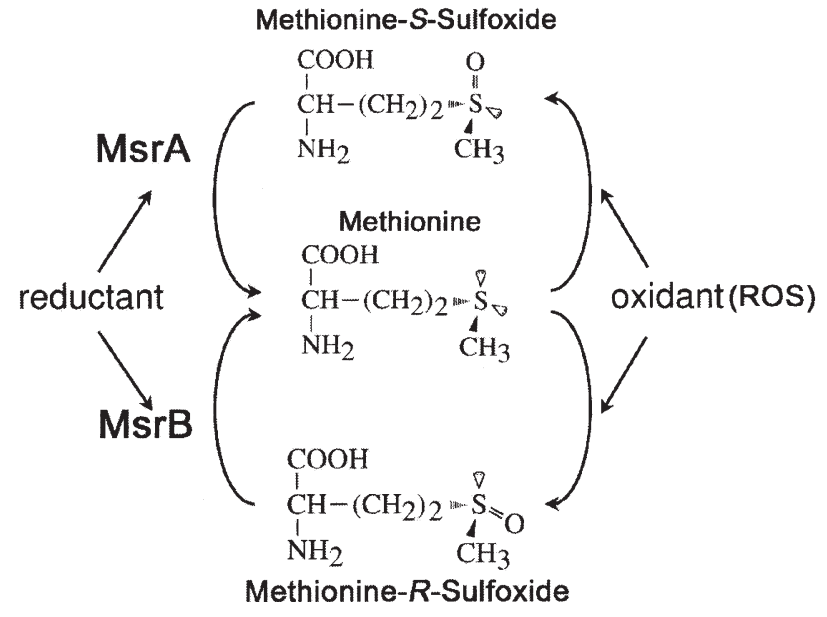

Figure 1. A pathway of methionine sulfoxide reduction. $R$ and $S$ diastereomers of methionine sulfoxide are formed directly or indirectly in free methionines and protein methionine residues in the presence of oxidants, such as hydrogen peroxide. Methionine- $S$-sulfoxides are reduced by MsrA and methionine- $R$-sulfoxides by MsrB with reductants, such as thioredoxin.

have been identified in the plant kingdom, for example in Arabidopsis thaliana $[21,22]$ and Chlamydomonas reinhardtii [23].

MsrA was discovered decades ago, and its function, catalytic mechanism, and structure are well understood [18,19,24-29]. MsrB has only recently been identified and is currently being extensively characterized [11,30-34]

\section{Mammalian methionine sulfoxide reductases}

Human and mouse genomes contain a single MsrA gene [35]. Mammalian MsrA has a typical N-terminal mitochondrial targeting peptide. Interestingly, however, this protein is located in cytosol and nucleus as well as in mitochondria [36-38]. Although molecular mechanisms responsible for targeting this protein to different cellular compartments are not fully understood, a recent study has shown that structural and functional elements of MsrA play a role in subcellular occurrence of this protein [38].

In contrast to a single MsrA gene [39,40], there are three MsrB genes in mammals [41]. MsrB1 (also known as selenoprotein R or selenoprotein X) $[9,10]$ is a selenoprotein in which Sec occupies the active site. This protein resides in the cytosol and nucleus. The other two MsrBs are homologous proteins in which Cys residues are present in place of Sec. MsrB2 (also known as CBS-1) $[32,42]$ is a mitochondrial protein. Interestingly, human MsrB3 occurs 
in two protein forms, MsrB3A and MsrB3B. These two forms are generated by alternative splicing of the first exon. The MsrB3A is targeted to the endoplasmic reticulum (ER), whereas MsrB3B is targeted to mitochondria [41]. However, there is no evidence for alternative splicing in the mouse MsrB3 gene. This protein contains the N-terminal ER signal followed by the mitochondrial signal sequence in a single coding region. This mouse MsrB3 form resides in the ER [43]. These findings of multiple cellular locations of MsrA and MsrB suggest that different compartments in mammalian cells maintain the methionine reduction system to repair oxidized methionine residues.

\section{Physiological roles of methionine sulfoxide reductases}

Reversible interconversion between methionine and methionine sulfoxide residues is implicated in several biological processes. Previously proposed functions of methionine sulfoxide reductases include repair of damaged proteins, antioxidant function as scavengers of ROS, and regulation of protein function $[44,45]$

A number of published reports describe the role of methionine sulfoxide reductases in antioxidant defense. For example, overexpression of MsrA protected $S$. cerevisiae and human T cells against oxidative stress [46], and the corresponding homologs were implicated in the protection against ROS in many microorganisms, such as Neisseria gonorrhoeae [47], Staphylococcus aureus [48], and Helicobacter pylori [49]. Recently, MsrA was found to promote viability of lens cells [50] and retinal pigmented epithelial cells [51] by conferring resistance to oxidative stress. In addition, MsrA can play a protective role against hypoxia/reoxygenation-mediated neuronal cell injury [52]. Lens MsrBs were also found to play a role in resistance to oxidative stress [53]. In addition, A. thaliana MsrA was reported to repair oxidatively damaged proteins during dark by reducing methionine sulfoxides in these proteins [21].

\section{Methionine sulfoxide reduction and aging}

Methionine sulfoxide reductases are directly implicated in regulation of the aging process. Research in this area has focused mainly on the effects of MsrA. Deletion of the MsrA gene in mice decreased the lifespan by 40\% [54], whereas overexpression of MsrA in Drosophila extended it by $70 \%$ [55]. The data that MsrA regulates lifespan in a variety of organisms raise a possibility that MsrB may also play an important role in the aging process. In particular, an attractive hypothesis has been advanced that since MsrB1 is a selenoprotein, dietary selenium supplementation may be used to increase expression of this protein. If MsrB1 regulates lifespan, elevated levels of this protein due to increased dietary intake of selenium may promote longevity in certain organisms or genetic backgrounds.
The role of MsrB in aging has recently been tested using $S$. cerevisiae as a model organism [56]. This protein was found to extend the yeast lifespan under caloric restriction conditions, whereas MsrA was most efficient under normal growth conditions. The lifespan extension required oxygen because it was found that neither MsrA nor MsrB regulate the lifespan of yeast cells grown under anaerobic conditions. In the future, deletion or overexpression of MsrB genes in mammals is needed to investigate the roles of these proteins in mammalian aging. Characterization of the effect of overexpression of MsrA on the lifespan in a mouse model also should be informative.

In addition to regulating lifespan, methionine sulfoxide reductases were directly implicated in aging-related neurodegenerative diseases, such as Alzheimer's and Parkinson's diseases [57-59].

\section{Selenoprotein forms of methionine sulfoxide reductases}

Although MsrBs are widely distributed in nature, the selenoprotein form of MsrB has only been found in vertebrates. In contrast, vertebrate MsrAs are Cys-containing proteins. Interestingly, a selenoprotein form of MsrA has also been identified, but could only be detected in $C$. reinhardtii, a unicellular green algae [23]. This Sec-containing MsrA has not been characterized. The observation that both classes of methionine sulfoxide reductase can occur in the form of selenoproteins suggests a catalytic advantage that Sec can offer in protection against oxidation of methionine residues.

\section{Catalytic properties and key role of selenium in MsrB}

Both bacteria and eukaryotes share basic features of the Sec insertion machinery, such as SECIS element, Sec tRNA, and SECIS-binding protein. However, a bacterial Sec insertion system also significantly differs from the mammalian system [3, 60-63]. For example, the conserved sequences and structures of SECIS elements are different in bacteria and eukaryotes. The location of these structures is also different: bacterial SECIS elements are present within coding regions, immediately downstream of Sec-coding UGA codons, whereas eukaryotic SECIS elements are located in the 3'-untranslated regions.

What is the role of the Sec residue in catalytic function of mammalian MsrB1? By site-directed mutagenesis, a bacterial SECIS element was introduced immediately downstream of the in-frame UGA Sec codon, and the recombinant Sec-containing MsrB1 was expressed in Escherichia coli [41]. This recombinant selenoprotein MsrB1 had four mutations (S99R, S100L, $\mathrm{K} 102 \mathrm{G}$, and F103P) compared to the wild type Sec-containing protein. The mutant exhibited $\sim 800$-fold higher enzyme activity than the corresponding Cys-containing form, indicating the essential role of Sec in this enzyme. In addition, a separate study reported that a recombinant Sec-containing MsrB1 
expressed from a construct that contained the entire E. coli formate dehydrogenase H SECIS element in the coding region, had 100-200 fold higher specific activity than the corresponding Cys mutant [64]. However, natural mammalian Cys-containing enzymes, MsrB2 and MsrB3, also showed a high enzyme activity [41].

Although the primary function of MsrA and MsrB is to catalyze the reduction of protein-based methionine sulfoxides, these enzymes can also reduce free methionine sulfoxides, albeit with low activity. Consistent with this property, all three mammalian MsrBs exhibited the activity in the conversion of free methionine- $R$-sulfoxide to methionine [41].

Some but not all MsrBs are zinc-containing proteins. This group of proteins includes all animal MsrBs, which contain a structural zinc coordinated by two CXXC motifs (two Cys separated by two other residues) $[11,41]$. Mutation of any zinc-coordinating Cys to Ser in Drosophila MsrB resulted in complete loss of metal and catalytic activity [34]. It has been suggested that zinc plays a structural role in metalloprotein MsrBs, and that this metal is not directly involved in the catalytic function $[34,65]$.

\section{Catalytic mechanisms of MsrB}

The reaction mechanism of MsrA has been characterized biochemically and is well supported by 3D structures [25-29]. Studies involving MsrBs from D. melanogaster, $N$. gonorrhoeae, and $N$. meningitides [24,34,66] revealed a similar catalytic mechanism. Interestingly, MsrA and MsrB folds are completely different [24,26-28,67]. MsrB functions in the following manner: 1) a catalytic Cys attacks sulfoxide moiety of the substrate resulting in the formation of sulfenic acid intermediate and concomitant release of methionine; 2) a resolving Cys attacks the sulfenic acid intermediate to form an intramolecular disulfide bond; and 3) a fully reduced enzyme is regenerated by reduction of the disulfide with Trx, a natural electron donor. DTT can also reduce the disulfide in in vitro assays.

Multiple sequence alignments showed that $\sim 60 \%$ of known MsrBs contain the conserved resolving Cys. The remaining $\sim 40 \%$ of $\mathrm{MsrB}$, including all three mammalian MsrBs, do not have this Cys. In addition, some bacterial MsrBs have only a single Cys in their sequences, suggesting the lack of any resolving Cys. How does the reaction proceed in these enzymes? Two alternative reaction mechanisms have been proposed. One is a direct reduction of the sulfenic acid intermediate by Trx. The other is the use of an alternative resolving Cys to form the intramolecular disulfide bond with the catalytic Cys. The second possibility is supported by the recent study of Xanthomonas campestris MsrB [68].

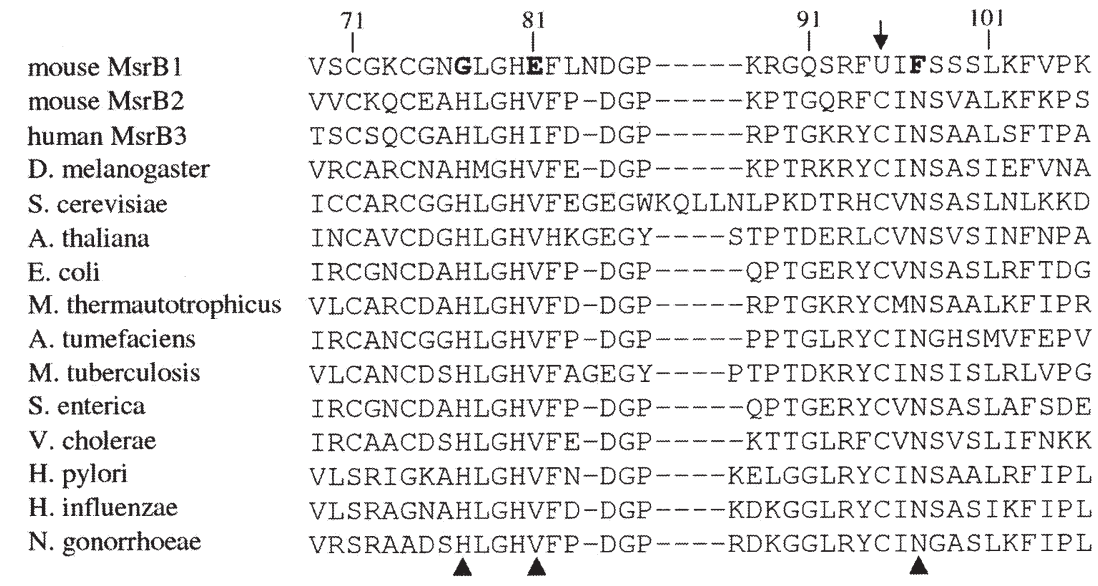

Figure 2. Partial alignment of Sec- and Cys-containing MsrBs. Catalytic Cys (C) and $\mathrm{Sec}(\mathrm{U})$ residues are shown by an arrow. The conserved His, Val/Ile, and Asn residues in Cys-containing proteins are indicated by arrowheads, and the corresponding residues (Gly, Glu, and Phe, respectively) in mouse selenoprotein MsrB1 are indicated by bold letters. Numbering of ammo acids is based on the mouse MsrB1 sequence. Cys 71 and Cys 74 coordinate zinc, and the corresponding $\mathrm{CxxC}$ motif is conserved in many, but not all MsrBs. Accession numbers (GI) are as follows: Mus musculus MsrB1, 7305478; M. musculus MsrB2, 27753987; Homo sapiens MsrB3, 72534836; Drosophila melanogaster, 17944415; Saccharomyces cerevisiae, 6319816; Arabidopsis thaliana, 4115939; Escherichia coli, 15802192; Methanothermobacter thermautotrophicus, 15678738; Agrobacterium tumefaciens, 15888246; Mycobacterium tuberculosis, 15609811; Salmonella enterica, 16760604; Vibrio cholerae, 15642000; Helicobacter pylori, 3252888; Hemophilus influenzae, 16273361; Neisseria gonorrhoeae, 19526685.

\section{Different sets of active site features in selenoprotein and non-selenoprotein MsrB}

Multiple sequence alignments reveal three highly conserved residues in MsrB sequences. These three residues are present in Cys-containing MsrBs, but absent in selenoprotein forms of this enzyme (Figure 2). It was previously found that these residues are part of the active site. Why did selenoprotein MsrBs evolve different residues in these positions? What are the roles of these residues in the catalytic function of selenoprotein and Cys-containing MsrBs?

It was recently found that the three residues uniquely conserved in Cys-containing MsrBs are critical for enzyme activity in MsrB2 and MsrB3, yet introducing these residues into MsrB1 inactivates this selenoprotein. Interestingly, when these residues are introduced into the Cys-containing mutant of MsrB1, the activity of this mutant increases several fold. Thus, the three residues are required for Cys-containing MsrB forms, but detrimental for the Sec-contain- 


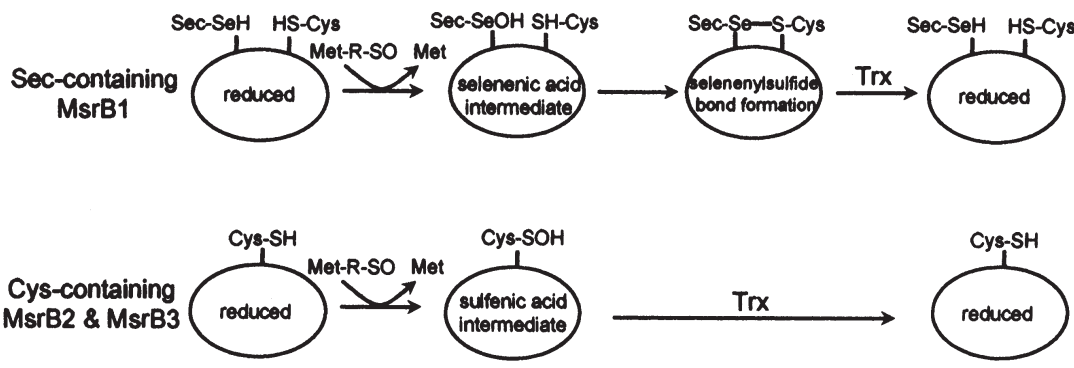

Figure 3. Models for catalytic mechanisms of Sec- and Cys-containing MsrBs. In Seccontaining MsrB1, the catalytic Sec attacks the methionine- $R$-sulfoxide (Met-R-SO) to form a selenenic acid intermediate, which interacts with a resolving Cys and forms a selenenylsulfide bond. This selenenylsulfide bond, subsequently, is reduced by Trx. In contrast, in Cys-containing MsrB2 and MsrB3, a sulfenic acid intermediate can be directly reduced by Trx because the resolving Cys is dispensable.

ing forms. These data suggested that Sec- and Cys-containing MsrBs evolve distinct sets of active site features to maximize their catalytic efficiencies.

\section{Different catalytic mechanisms between selenoprotein and}

\section{non-selenoprotein mammalian MsrBs}

As discussed above, many selenoproteins have fully functional orthologs, wherein Cys replaces Sec. These Cys orthologs are often catalytically as efficient as selenoprotein forms. The reason why Sec is used in proteins if the Cys versions are sufficient for their functions is only beginning to be understood. The three mammalian MsrBs offer a great model system to address these questions which are central to the role of selenium in biology. We recently reported that selenoprotein and non-selenoprotein forms of mammalian MsrBs employ different catalytic mechanisms with respect to the regeneration of the fully reduced proteins (Figure 3) [69].

As shown in Figure 3, the selenoprotein MsrB1 requires a unique resolving Cys for recycling of the enzyme. A selenenic acid intermediate of MsrB1 is engaged in a selenenylsulfide bond with resolving Cys located in the N-terminal part of the protein. Mutation of this Cys to Ser results in complete loss of enzyme activity in the Trx-dependent reaction but not in the DTT-dependent reaction. Subsequently, the selenenylsulfide is reduced by a physiological electron donor, Trx. It appears that the selenenic acid intermediate cannot be reduced by Trx but is reducible by DTT. In contrast, mutational analyses revealed that the resolving Cys is not needed for Cys-containing MsrB2 and MsrB3, in which the sulfenic acid intermediate is likely directly reduced by Trx.
Catalytic advantages and disadvantages of Sec-containing proteins compared to Cys-containing counterparts

The data on Sec- and Cys-containing MsrBs suggested that Sec per se may result in a higher catalytic activity. Replacement of Cys with Sec in mammalian MsrB2 and MsrB3 increased the activity over 100 fold in the DTTdependent reaction [69]. It has been previously reported that the catalytic activity of phospholipid hydroperoxide glutathione peroxidase can also be increased by replacing the active site Cys with Sec [70]. Thus, the enhanced catalytic activity of selenoproteins can explain, at least in part, the advantage of Sec over Cys. However, replacement of Cys with Sec may not only influence enzyme activity, but also alter protein function. For instance, a Seccontaining form of subtilisin is an efficient peroxidase rather than a protease [71]. The use of Sec in glutathione S-transferase also changed this protein to a peroxidase [72].

Are there any other advantages of the use of selenium besides enhancing enzyme activity? A recent study has shown that the presence of a unique Cterminal active site in Drosophila thioredoxin reductase (SCCS instead of GCUG in mammalian enzymes) can convert this protein into a highly active enzyme [73]. This study suggested that the advantages of selenoenzymes are in a broader range of substrates and flexibility of microenvironmental conditions in the active sites.

It appears that the use of Sec can also result in catalytic disadvantages. Although the mutant Sec-containing forms of MsrB2 and MsrB3 are characterized by a 100 -fold increased methionine sulfoxide reductase activity, regeneration of the active enzymes by natural electron donor (e.g., Trx) is not possible [69]. However, by introducing a unique resolving Cys, the selenoprotein form of MsrB3 can become as active as the natural Cys-containing enzyme in the Trx-dependent reaction [69].

\section{Evolutionary implications}

Most selenoprotein forms likely evolved by replacing catalytic Cys with Sec, which equips oxidoreductases with enhanced activity. However, this evolutionary process is more complex than a simple change of a Cys codon to TGA. The changes must also involve the generation of SECIS elements. Furthermore, Sec may evolve only in environments where selenium is present in sufficient levels and in organisms with active Sec insertion system. Clearly, although replacement of catalytic redox Cys with Sec may be expected to enhance protein function, other requirements should be satisfied. These and other factors may limit the use of Sec in biological systems. 


\section{Acknowledgments}

This work was supported by NIH AG021518 to VNG.

\section{References}

1. TC Stadtman 1996 Annu Rev Biochem 65:83

2. JF Atkins, RF Gesteland 2000 Nature 407:463

3. DL Hatfield, VN Gladyshev $2002 \mathrm{Mol}$ Cell Biol 22:3565

4. GV Kryukov, S Castellano, SV Novoselov, AV Lobanov, O Zehtab, R Guigo, VN Gladyshev 2003 Science 300:1439

5. I Chambers, J Frampton, P Goldfarb, N Affara, W McBain, PR Harrison 1986 EMBO J 5:1221

6. VN Gladyshev, KT Jeang, TC Stadtman 1996 Proc Natl Acad Sci USA 93:6146

7. F Zinoni, A Birkmann, TC Stadtman, A Bock 1986 Proc Natl Acad Sci USA 83:4650

8. A Bock, K Forchhammer, J Heider, C Baron 1991 Trends Biochem Sci 16:463

9. GV Kryukov, VM Kryukov, VN Gladyshev 1999 J Biol Chem 274:33888

10. A Lescure, D Gautheret, P Carbon, A Krol 1999 J Biol Chem 274:38147

11. GV Kryukov, RA Kumar, A Koc, Z Sun, VN Gladyshev 2002 Proc Natl Acad Sci USA 99:4245-4250

12. C Jacob, GI Giles, NM Giles, H Sies 2003 Angew Chem Int Ed 42:4742

13. H Weissbach, F Etienne, T Hoshi, SH Heinemann, WT Lowther, BW Matthews, G St. John, C Nathan, N Brot 2002 Arch Biochem Biophys 397:172

14. H Weissbach, L Resnick, N Brot 2005 Biochim Biophys Acta 1703:203

15. I Petropoulos, B Friguet 2005 Biochim Biophys Acta 1703:261

16. ER Stadtman, H Van Remmen, A Richardson, NB Wehr, RL Levine 2005 Biochim Biophys Acta 1703:135

17. J Moskovitz 2005 Biochim Biophys Acta 1703:213

18. N Brot, L Weissbach, J Werth, H Weissbach 1981 Proc Natl Acad Sci USA 78:2155

19. N Brot, H Weissbach 1983 Arch Biochem Biophys 223:271

20. B Ezraty, L Aussel, F Ban-as 2005 Biochim Biophys Acta 1703:221

21. U Bechtold, DJ Murphy, PM Mullineaux 2004 Plant Cell 16:908-919

22. CV Dos Santos, S Cuine, N Rouhier, P Rey 2005 Plant Physiol 138:909

23. SV Novoselov, M Rao, NV Onoshko, H Zhi, GV Kryukov, Y Xiang, DP Weeks, DL Hatfield, VN Gladyshev 2002 EMBO J 21:3681

24. WT Lowther, H Weissbach, F Etienne, N Brot, BW Matthews 2002 Nat Struct Biol 9:348

25. WT Lowther, N Brot, H Weissbach, JF Honek, BW Matthews 2000 Proc Natl Acad Sci USA 97:463

26. WT Lowther, N Brot, H Weissbach, BW Matthews 2000 Biochemistry 39:13307

27. F Tete-Favier, D Cobessi, S Boschi-Muller, S Azza, G Branlant, A Aubry 2000 Structure $8: 1167$

28. AB Taylor, DM Benglis Jr, S Dhandayuthapani, PJ Hart 2003 J Bacterial 185:4119

29. M Antoine, S Boschi-Muller, G Branlant 2003 J Biol Chem 278:45352

30. A Olry, S Boschi-Muller, M Marraud, S Sanglier-Cianferani, A Van Dorsselear, G Branlan 2002 J Biol Chem 277:12016

31. R Grimaud, B Ezraty, JK Mitchell, D Lafitte, C Briand, PJ Derrick, F Barras 2001 J Biol Chem 276:48915

32. S Jung, A Hansel, H Kasperczyk, T Hoshi, SH Heinemann 2002 FEBS Lett 527:91

33. F Etienne, D Spector, N Brot, H Weissbach 2003 Biochem Biophys Res Commun 300:378

34. RA Kumar, A Koc, RL Cemy, VN Gladyshev 2002 J Biol Chem 277:37527

35. A Hansel, SH Heinemann, T Hoshi 2005 Biochim Biophys Acta 1703.23

36. A Hansel, L Kuschel, S Hehl, C Lemke, HJ Agricola, T Hoshi, SH Heinemann 2002 FASEBJ 16:911
37. S Vougier, J Mary, B Friguet 2003 Biochem J 373:531

38. HY Kirn, VN Gladyshev 2005 Biochemistry 44:8059

39. J Moskovitz, H Weissbach, N Brot 1996 Proc Natl Acad Sci USA 93:2095

40. L Kuschel, A Hansel, R Schonherr, H Weissbach, N Brot, T Hoshi, SH Heinemann 1999 FEBS Lett 456:17

41. HY Kirn, VN Gladyshev 2004 Mol Biol Cell 15:1055

42. W Huang, J Escribano, M Sarfarazi, M Coca-Prados 1999 Gene 233:233

43. HY Kim, VN Gladyshev 2004 Biochem Biophys Res Commun 320:1277

44. RL Levine, J Moskovitz, ER Stadtman 2000 IUBMB Life 50:301

45. ER Stadtman, J Moskovitz, RL Levine 2003 Antioxid Redox Signal 5:577

46. J Moskovitz, E Flescher, BS Berlett, J Azare, JM Poston, ER Stadtman 1998 Proc Natl Acad Sci USA 95:14071

47. EP Skaar, DM Tobiason, J Quick, RC Judd, H Weissbach, F Etienne, N Brot, HS Seifert 2002 Proc Natl Acad Sci USA 99:10108

48. VK Singh, J Moskovitz 2003 Microbiology 149:2739

49. P Alamuri, RJ Maier 2004 Mol Microbiol 53:1397

50. M Kantorow, JR Hawse, TL Cowell, S Benhamed, GO Pizarro, VN Reddy, JF Hejtmancik 2004 Proc Natl Acad Sci USA 101:9654

51. PG Sreekumar, R Kannan, J Yaung, CK Spec, SJ Ryan, DR Hinton 2005 Biochem Biophys Res Commun 334:245

52. O Yermolaieva, R Xu, C Schinstock, N Brot, H Weissbach, SH Heinemann, T Hoshi 2004 Proc Natl Acad Sci USA 101:1159

53. MA Marchetti, GO Pizarro, D Sagher, C Deamicis, N Brot, JF Hejtmancik, H Weissbach, M Kantorow 2005 Invest Ophthalmol Vis Sci 46:2107

54. J Moskovitz, S Bar-Noy, WM Williams, J Requena, BS Berlett, ER Stadtman 2001 Proc Nat Acad Sci USA 98:12920

55. H Ruan, XD Tang, ML Chen, ML Joiner, G Sun, N Brot, H Weissbach, SH Heinemann, L Iverson, CF Wu, T Hoshi 2002 Proc Natl Acad Sci USA 99:2748

56. A Koc, AP Gasch, JC Rutherford, HY Kim, VN Gladyshev 2004 Proc Natl Acad Sci USA 101:7999

57. SP Gabbita, MY Aksenov, MA Lovell, WR Markesbery 1999 J Neurochem 73:1660

58. C Schoneich 2005 Biochim Biophys Acta 1703:111

59. CB Glaser, G Yamin, VN Uversky, AL Fink 2005 Biochim Biophys Acta 1703:157

60. Z Liu, M Reches, I Groisman, H Engelberg-Kulka 1998 Nucleic Acids Res 26:896

61. KE Sandman, CJ Noren 2000 Nucleic Acids Res 28:755

62. ES Amer, H Sarioglu, F Lottspeich, A Holmgren, A Bock J Mol Biol 292:1003

63. F Zinoni, J Heider, A Bock 1990 Proc Natl Acad Sci USA 87:4660

64. S Bar-Noy, J Moskovitz 2002 Biochem Biophys Res Commun 297:956

65. A Olry, S Boschi-Muller, H Yu, D Bumel, G Branlant 2005 Protein Sci 14:2828

66. A Olry, S Boschi-Muller, G Branlant 2004 Biochemistry 43:11616

67. B Kauffinann, A Aubry, F Favier 2005 Biochim Biophys Acta 1703:249

68. F Neiers, A Kriznik, S Boschi-Muller, G Branlant 2004 J Biol Chem 279:42462.

69. HY Kim, VN Gladyshev 2005 PLoS Biol 3 :e375

70. S Hazebrouck, L Camoin, Z Faltin, AD Strosberg, Y Eshdat 2000 J Biol Chem 275:28715

71. IM Bell, ML Fisher, ZP Wu, D Hilvert 1993 Biochemistry 32:3754

72. HJ Yu, JQ Liu, A Bock, J Li, GM Luo, JC Shen 2005 J Biol Chem 280:11930

73. S Gromer, L Johansson, H Bauer, LD Arscott, S Rauch, DP Ballou, CH Williams Jr, RH Schirmer, ES Amer 2003 Proc Natl Acad Sci USA 100:12618 